Article

\title{
Risk Coupling Characteristics of Maritime Accidents in Chinese Inland and Coastal Waters Based on N-K Model
}

\author{
Jian Deng ${ }^{1,2,3}$, Shaoyong Liu ${ }^{1}$, Cheng Xie ${ }^{1,2, *}$ and Kezhong Liu ${ }^{1,2,3}$ \\ 1 School of Navigation, Wuhan University of Technology, Wuhan 430070, China; \\ dengjian_whut@163.com (J.D.); Liushaoyong@whut.edu.cn (S.L.); kzliu@whut.edu.cn (K.L.) \\ 2 Hubei Key Laboratory of Inland Shipping Technology, Wuhan 430000, China \\ 3 National Engineering Research Center for Water Transport Safety, Wuhan 430000, China \\ * Correspondence: cxie@whut.edu.cn; Tel.: +86-18674060301
}

check for updates

Citation: Deng, J.; Liu, S.; Xie, C.; Liu, K. Risk Coupling Characteristics of Maritime Accidents in Chinese

Inland and Coastal Waters Based on N-K Model. J. Mar. Sci. Eng. 2022, 10, 4. https://doi.org/10.3390/ jmse10010004

Academic Editor: Claudio Ferrari

Received: 29 November 2021

Accepted: 18 December 2021

Published: 21 December 2021

Publisher's Note: MDPI stays neutral with regard to jurisdictional claims in published maps and institutional affiliations.

Copyright: (C) 2021 by the authors. Licensee MDPI, Basel, Switzerland. This article is an open access article distributed under the terms and conditions of the Creative Commons Attribution (CC BY) license (https:// creativecommons.org/licenses/by/ $4.0 /)$.

\begin{abstract}
The causes of maritime accidents are complex, mostly due to the coupling of four types of factors: human-ship-environmental-management. To effectively analyze the causes of maritime accidents in China, and reveal the risk coupling characteristics of accidents, this paper establishes the N-K model of maritime accident, and calculates and analyzes the four types of coupling of risk factors affecting safety in maritime traffic. This paper collects 922 maritime accidents that occurred in China from 2000 to 2020, and analyzes the location, type, and level of accidents and uses the trigger principle to describe the process of accidents. For marine and inland river accidents, this paper calculates the four types of coupling values of risk factors (single-factor coupling, two-factor coupling, three-factor coupling, four-factor coupling) for comparison and analysis. In addition, this paper calculates the coupling values of six typical maritime accidents of collision, sinking, contact, fire/explosion, stranding, grounding. According to the coupling values and the frequency of subfactors, this paper analyzes the coupling characteristics of maritime accidents. The results show that in maritime accidents, as the number of risk factors participating in the coupling increases, the coupling value increases, and the multi-factor coupling is more likely to cause accidents. The overall situation of risk coupling causes of maritime accidents is basically consistent with inland river accidents, but they have their own characteristics in the specific degree of risk coupling and the dominant risk elements. In different types of maritime accidents, the risk coupling has different characteristics, and the dominant risk factors are also different.
\end{abstract}

Keywords: maritime accident; risk coupling; N-K model; characteristic

\section{Introduction}

With the development of China's economy and the intensification of internationalization, waterway transportation has developed rapidly and has become a major mode of transportation. In 2020, China's waterway freight volume has reached 7.6 billion tons [1]. With the increasingly busy water traffic, associated safety risks also increase, and maritime accidents occur occasionally. Due to the large tonnage of ships and the large number of passengers and cargoes carried, the share of cargoes that are highly hazardous to the environment is considerable [2]. If an accident occurs, it often easily results in casualties and property loss, and may even seriously pollute the aquatic environment. Therefore, the effective and scientific prevention of the occurrence of maritime accidents has always been the focus of all levels of China's management departments. Many factors affect the safety of water transportation and their relationship is complicated. The water transportation risk factor itself is the root cause of the water transportation risk problem and the starting point of maritime accidents. Usually, a single risk factor will not cause large system failure. When multiple risk factors interact, superimpose, and magnify, system failure may occur. Therefore, analyzing and studying the coupling characteristics of maritime safety risk factors is a key step of the effective prevention and control of maritime accidents. These measures are also key to improving the risk management level. 
The causes and mechanisms of maritime accidents have always been a hot issue both in China and internationally. Mou et al. [3] monitored the traffic at the Port of Rotterdam based on the SAMSON method and identified the minimum encounter distance as a key indicator to avoid ship collisions. Antao and Guedes Soaress [4] established an accident tree model for ro-ro ships and presented an analysis of key human factors. Kim et al. [5] introduced the system theory accident model and process analysis method and, for the first time, applied it for a cause analysis of passenger ship accidents; they also studied the cause mechanism of the shipwreck accident of the "Shi Yue" ferry. Szczepaniak et al. [6] used the finite element method to analyze the causes of accidents of military aircraft. Zhang et al. [7] constructed an accident cause model combining functional resonance analysis and fuzzy analytic hierarchy process to analyze ship collision accidents. Liu and Zheng [8] established a cause analysis network for ship collision accidents based on Petri nets and ship collision accident investigation reports. Recently, research on the coupling causes of maritime accidents has gradually gained increasing attention. Liu and Wang [9] used the risk coupling analysis method for a risk analysis and measurement of the navigation safety of ships in complex waters (Ice areas, islands and reef areas, shallow water areas, narrow waterways, etc. are regarded as complex waters), and provided a theoretical basis for the navigation safety management of complex waters. Wang and Liu [10] applied the $\mathrm{N}-\mathrm{K}$ model to build a maritime traffic safety risk coupling measurement model, which was combined with domestic and foreign accident statistics, to calculate the occurrence probability and risk value of different risk couplings. Lou and Liu [11] used the N-K model to perform coupling calculations on unsafe air traffic control events over the preceding 10 years, and evaluated the safety risk status of air traffic control. Xue et al. [12] established a risk coupling model using system dynamics, for the risk assessment of high-speed rail projects, and evaluated the risk level during the simulation period of high-speed rail projects. Jiao et al. [13] proposed a joint evaluation technology of decision-making trial and evaluation laboratory model and Bayesian network to evaluate the risk of coupling factors during aircraft take-off.

From both Chinese and international research, the causes of maritime accidents have been extensively researched, and a variety of research methods have been adopted such as machine learning [14], the Bayesian Spatio-temporal (BS) model [15], etc. In recent years, research on the coupling of risk factors has attracted increasing attention and has made certain progress. [11] The current research on the coupling of maritime safety risk factors mainly focuses on the overall systematic research. However, there are many types of maritime accidents, and their geographical location and navigation environment are quite different. Whether the coupling characteristics of the risk factors of maritime and inland river accidents are consistent remains to be assessed. Furthermore, the differences in the risk coupling characteristics of different types of accidents (e.g., ship fires, collisions, and groundings) also remain unknown. These issues require in-depth research and discussion. By applying the N-K model, this paper classifies and studies the causes of different types of maritime accidents and discusses the classification characteristics of the coupling of maritime risk factors. In this way, a more detailed description of the cause mechanism of maritime accidents is obtained, which provides a basis for the formulation of prevention and maritime accident control measures.

\section{Materials}

\subsection{Accident Data}

To effectively conduct research on the coupling characteristics of maritime safety risk factors in Chinese waters, this paper collected 922 maritime accidents that were reported to China's maritime administration department from 2000 to 2020. Relevant research and analysis were carried out based on these detailed accident investigation reports.

All maritime accidents studied in this paper occurred in China's coastal and inland waters, and include 620 accidents in coastal waters and 302 in inland waters. Figure 1 shows the geographical distribution of all 922 maritime accidents. According to the heat 
map of accident locations, the maritime accident area along the coast of China is spread over the entire coastal waters of China. The frequency of accidents increases with closer proximity to the coastline. Three sea areas with more concentrated maritime accidents have formed along the coast of China: the Bohai Sea, the Yangtze River estuary waters, and the Pearl River estuary waters. China's inland river accidents are mainly concentrated in the main stream of the Yangtze River and the main stream of the Xijiang River. The highest frequency of accidents occurs in the lower reaches of the Yangtze River and the lower reaches of the Xijiang River. In general, areas where maritime accidents occur are mostly waters with a large ship flow and a complex navigational environment.

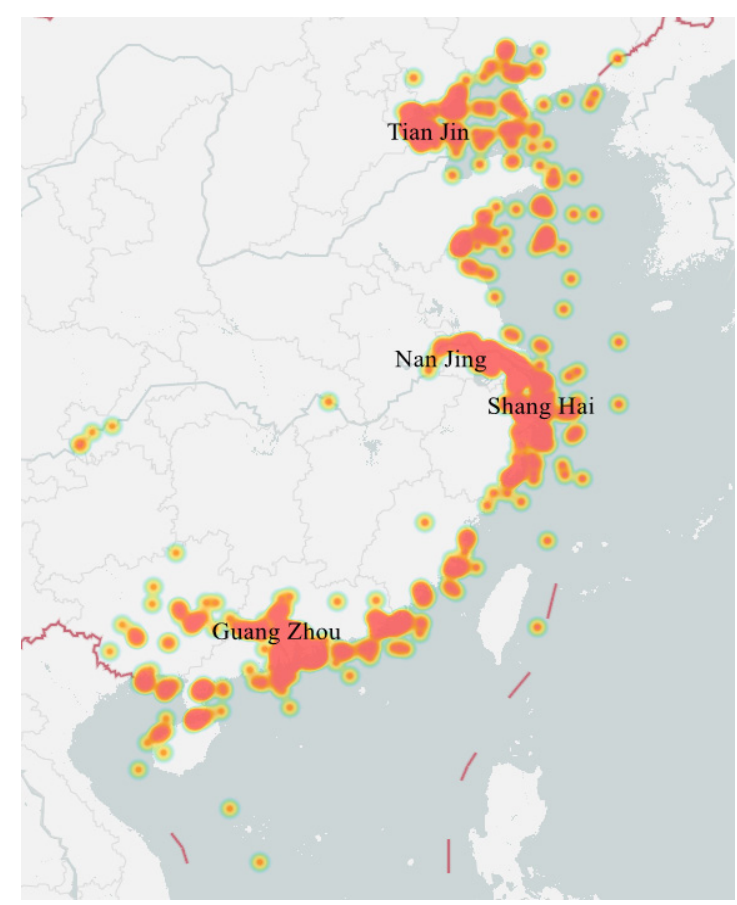

Figure 1. Heat map of the locations of maritime accidents along the Chinese coastline.

According to the "Statistical Measures for Maritime accidents of the People's Republic of China" [16], maritime accidents are mainly divided into 10 categories: collision, stranding, rocking, contact, wave damage, fire/explosion, wind disaster, self-sinking, operational pollution, and a number of other maritime accidents that result in casualties, direct economic losses, or pollution of the water environment. According to this classification, the 922 maritime accidents assessed in this paper were classified as: 377 collisions, 162 sinking, 73 contact damage, 36 wind damage, 47 fires/explosions, 29 stranding events, 33 grounding events, and 165 events classified as "others". Collision accidents are the most frequent maritime accidents, followed by sinking and contact damage with higher frequencies. Specific as shown in Figure 2.

According to the "Statistical Measures for Maritime accidents of the People's Republic of China", maritime accidents are divided into five levels according to their severity: particular major accidents, major accidents, larger accidents, general accidents, and small accidents. Among the 922 accidents analyzed in this paper, zero were particular major accidents, 37 were major accidents, 121 were larger accidents, 592 were general accidents, and 172 were small accidents. Specific as shown in Figure 3. This shows that overall, the vast majority of maritime accidents in China are accidents of general grade and below, which together, account for $82 \%$ of the total number of accidents. Accidents of the general grade account for the largest proportion, reaching $64.2 \%$. In addition, in terms of the number of dead, missing, and injured as a result of different types of accidents, as shown in Figure 4, collision accidents caused the most casualties, followed by sinking accidents. 


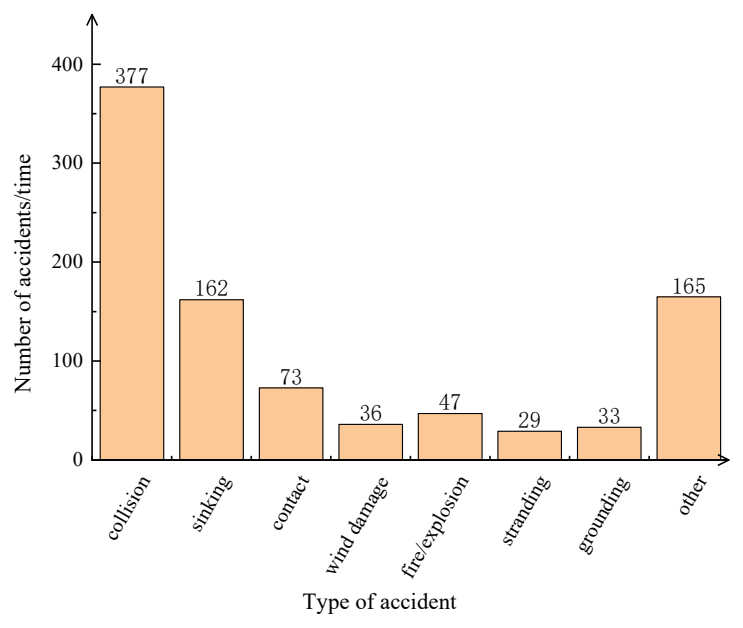

Figure 2. Occurrences of different types of accidents.

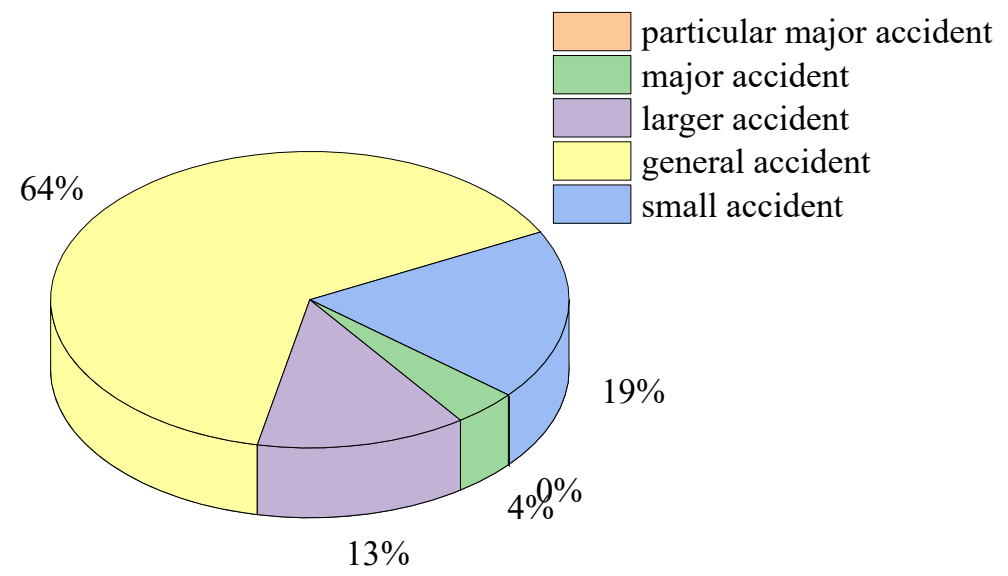

Figure 3. Distribution of accident levels.

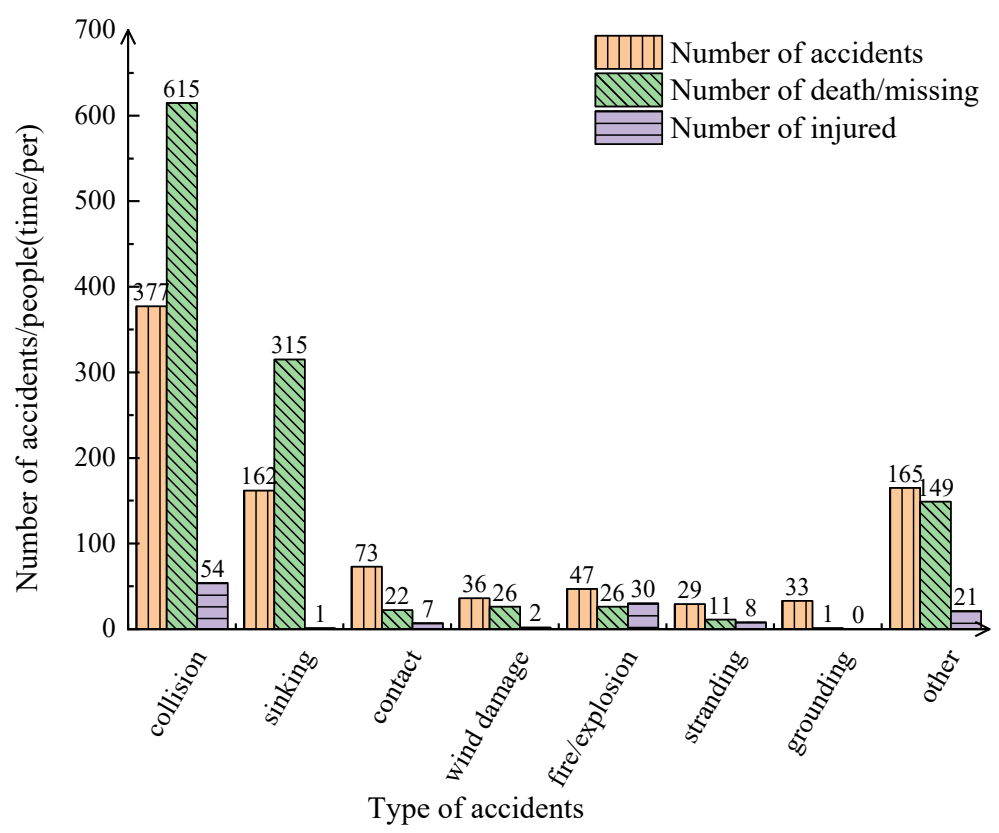

Figure 4. Numbers of total accidents, deaths and missing, and injured. 


\subsection{Risk Factor Data}

The maritime safety system is a complex and dynamic system. According to the system engineering theory, the factors affecting maritime safety can be roughly divided into the following four categories: human risk factors, ship risk factors, navigation environment risk factors, and management risk factors. Each aspect can be further subdivided into more specific risk factors.

Human risk factors [17] refer to the risks caused by the subjective influence of people, such as ship driving, ship maneuvering, coordinated avoidance, and the implementation of conventions and rules in the maritime safety system. These mainly include the physiological condition, psychological condition, knowledge and skill level, and practical experience of the crew, as well as their communication and execution abilities.

Ship risk factors refer to the equipment, condition, method of use, and degree of use of relevant equipment and facilities surrounding the ship as the main means of transport in the operation of the maritime safety system. These also include the characteristics of the cargo, the stowage and securing state, the hull structure, ship cargo, ship information, ship machinery and equipment, ship electronic equipment, and other risks.

Environmental risk factors [18] refer to the risks caused by the natural environment, channel environment, and personnel construction environment in the operation of the maritime safety system. These mainly include the natural environment (e.g., wind, waves, current, and visibility), the channel environment (e.g., channel size and ship density), and the construction operation environment (e.g., lighting of the workplace and ventilation of confined spaces).

Management risk factors refer to the risks caused by the management responsibilities of the ships and crews of relevant agencies, shipping companies, owners, and operators that ensure safe operation of the maritime safety system. These mainly include crew deployment and competency, the degree of observance of rules and regulations, corporate culture, training and education, organizational capabilities, decision-making capabilities, and shore-based support.

The causes of all assessed 922 maritime accidents in Chinese waters involved the following four major categories: human factors, ship factors, environmental factors, and management factors. Most of these involve more than two factors. The specific cause classification is presented in Table ??. Figure 5 shows the proportion of various risk factors among maritime accidents. The order of the causes of maritime accidents is human factors $>$ ship factors $>$ management factors $>$ environmental factors. Among them, more than $90 \%$ of all maritime accidents involve human factors, and ship factors and management factors also account for a larger proportion, accounting for $44.5 \%$ and $42.6 \%$, respectively. Environmental factors account for a relatively small proportion of $23.4 \%$. Among inland river accidents, the ranking of the causes of maritime accidents is relatively consistent, but human factors account for a larger proportion than those at sea. However, ship factors, environmental factors, and management factors account for lower proportions of traffic accidents in inland rivers than at sea. This result shows that the risk of accidents caused by human factors is higher in inland rivers.

Table 1. Statistic of risk factors of inland river and marine accidents.

\begin{tabular}{ccccc}
\hline & Human Factors & Ship Factors & Environmental Factors & Management Factors \\
\hline Marine (620) & 550 & 295 & 155 & 288 \\
Inland river (302) & 283 & 116 & 61 & 105 \\
\hline
\end{tabular}

To further analyze the specific causes of maritime accidents, this paper analyzes the specific causes of accidents and statistics based on the investigation reports of the assessed 922 maritime accidents as shown in Table 2. The serial number in the table is random and does not represent a certain order. 


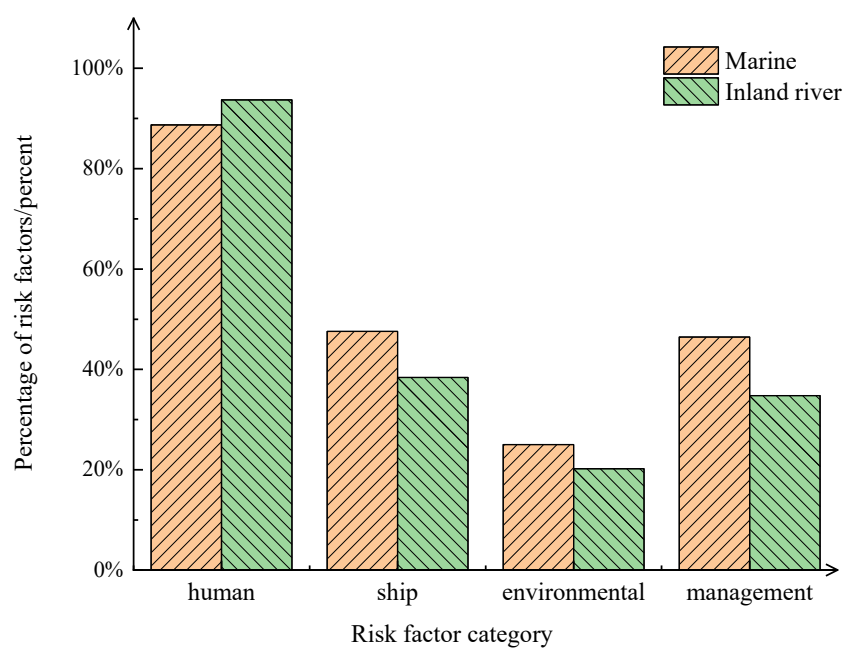

Figure 5. Proportion of various risk factors in the marine and inland rivers.

Table 2. Numbers of sub-factors of marine and inland river risk factors.

\begin{tabular}{|c|c|c|c|c|c|}
\hline & Number & Human Factors & Ship Factors & Environmental Factors & Management Factors \\
\hline \multirow{16}{*}{ Marine } & 1 & Negligent watch (247) & Ship uninspected (25) & Wind (99) & \multirow{2}{*}{$\begin{array}{l}\text { Insufficient manning (92) } \\
\text { Incomplete safety management } \\
\text { system (29) }\end{array}$} \\
\hline & 2 & Unused safe speed (116) & Overload (17) & Wave (67) & \\
\hline & 3 & Illegal operation (99) & Overrun area (53) & Flow (19) & \multirow{3}{*}{$\begin{array}{l}\text { Lack of shore-based support (37) } \\
\text { Disorganized emergency training (7) } \\
\text { Unsuitable crew (130) }\end{array}$} \\
\hline & 4 & Improper operation (77) & Unballasted (3) & Visibility (12) & \\
\hline & 5 & Insufficient skill level (101) & High ship age (11) & Rain (4) & \\
\hline & 6 & Inexperienced (147) & Missing equipment (45) & Complex water environment (27) & $\begin{array}{l}\text { Unsuitable crew (130) } \\
\text { Imperfect emergency plan (5) }\end{array}$ \\
\hline & 7 & Failure to take early action (160) & Missing books and materials (13) & - & \multirow{2}{*}{$\begin{array}{l}\text { Lack of training }(42) \\
\text { Insufficient supervision (27) }\end{array}$} \\
\hline & 8 & Poor communication (39) & $\begin{array}{l}\text { Equipment failure (90) } \\
\text { Eald }\end{array}$ & - & \\
\hline & 9 & Unfamiliar water environment (37) & Improper cargo stowage (30) & - & $\begin{array}{l}\text { Imperfect system (25) } \\
\text { Inste }\end{array}$ \\
\hline & 10 & Unfamiliar water environment (98) & Lack of maintenance (24) & - & Lack of management (90) \\
\hline & 11 & Low security awareness (96) & Unsealed cabin trimming (34) & - & \multirow{2}{*}{ - } \\
\hline & 12 & Improper duty (53) & Illegal modification (12) & - & \\
\hline & 13 & Fatigue (4) & - & - & \multirow{2}{*}{ 二 } \\
\hline & 14 & Improper route maintenance (35) & - & - & \\
\hline & 15 & Improper use of equipment (45) & - & - & \multirow{2}{*}{ 二 } \\
\hline & 16 & Driving without caution (46) & - & - & \\
\hline \multirow{16}{*}{ Inland river } & 1 & Negligent watch (107) & Ship uninspected (18) & Wind $(30)$ & \multirow{2}{*}{$\begin{array}{l}\text { Insufficient manning (14) } \\
\text { Incomplete safety management } \\
\text { system (20) }\end{array}$} \\
\hline & 2 & Unused safe speed (39) & Overload (19) & Wave (11) & \\
\hline & 3 & Illegal operation (49) & Overrun area (1) & Flow (20) & \\
\hline & 4 & Improper operation (58) & Unballasted (2) & Visibility (5) & \\
\hline & 5 & Insufficient skill level (31) & High ship age (2) & Rain $(7)$ & $\begin{array}{l}\text { Disorganized emergency training (4) } \\
\text { Unsuitable crew (28) }\end{array}$ \\
\hline & 6 & Inexperienced (58) & Missing equipment (24) & Complex water environment (9) & Imperfect emergency plan (4) \\
\hline & 7 & Failure to take early action (63) & Missing books and materials (4) & - & Lack of training (29) \\
\hline & 8 & Poor communication (14) & Equipment failure (27) & - & Insufficient supervision (14) \\
\hline & 9 & Unfamiliar water environment (13) & Improper cargo stowage securing (9) & - & \multirow{2}{*}{$\begin{array}{l}\text { Imperfect system (17) } \\
\text { Lack of management (48) }\end{array}$} \\
\hline & 10 & Unfamiliar water environment (48) & Lack of maintenance (7) & - & \\
\hline & 11 & Low security awareness (77) & Unsealed cabin trimming (16) & - & \multirow{2}{*}{ 二 } \\
\hline & 12 & Improper duty (20) & Illegal modification (10) & - & \\
\hline & 13 & Fatigue (4) & - & - & - \\
\hline & 14 & Improper route maintenance (23) & - & - & \multirow{3}{*}{ 二 } \\
\hline & 15 & Improper use of equipment (22) & - & - & \\
\hline & 16 & Driving without caution (33) & - & - & \\
\hline
\end{tabular}

Among human factors, the main reasons for accidents include negligence, failure to use safe speed, illegal operation, improper operation, insufficient skill level, insufficient experience, failure to take early action, poor communication, unfamiliar water environment, improper emergency response, weak safety awareness, improper duty, improper route maintenance, improper use of equipment, improper driving, fatigue, and other factors.

Among ship factors, the main reasons for accidents include uninspected ship, overloading, overrun area, unballasted, high ship age, missing equipment, missing books and materials, equipment failure, improper cargo stowage, lack of maintenance, unsealed cabin trimming, illegal modifications, and other factors.

Among environmental factors, the main causes of accidents include factors such as wind, waves, currents, visibility, rain, and complex water environment.

Among management factors, the main causes of accidents include insufficient manning, unsuitable crew, incomplete safety management system, imperfect emergency plan, imperfect system, disorganized emergency training, lack of training, lack of management, lack of shore-based support, insufficient supervision, and other factors. 
Through the statistics of the number of risk factors and sub-factors as described by accident reports, the proportion of the number of risk factors and sub-factors is obtained. The frequency of risk sub-factors in inland river and marine accidents is compared and analyzed and the results are depicted in Figures 6-9.

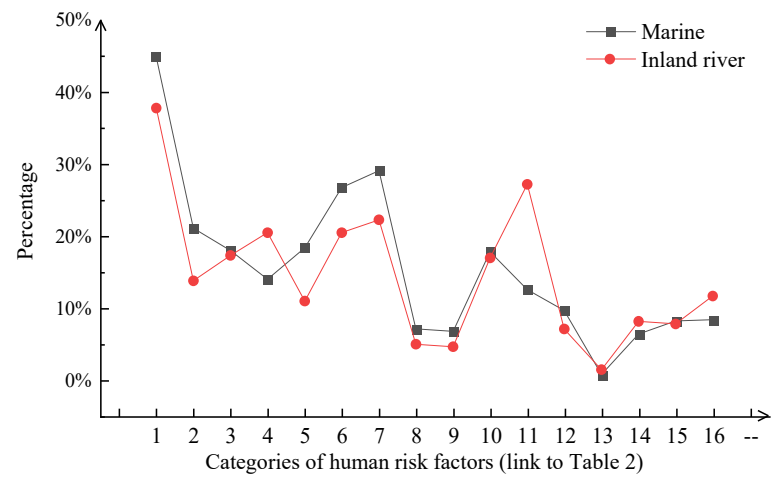

Figure 6. Proportion of Sub-Factors of Marine and Inland River Human Factors.

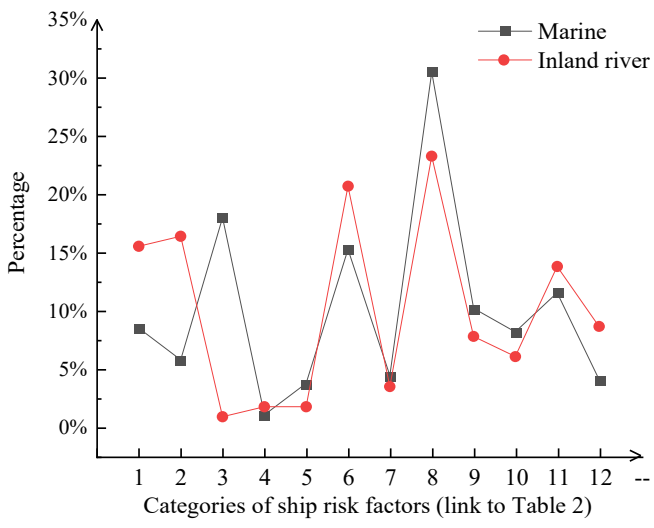

Figure 7. Proportion of Sub-Factors of Marine and Inland Ship Factors.

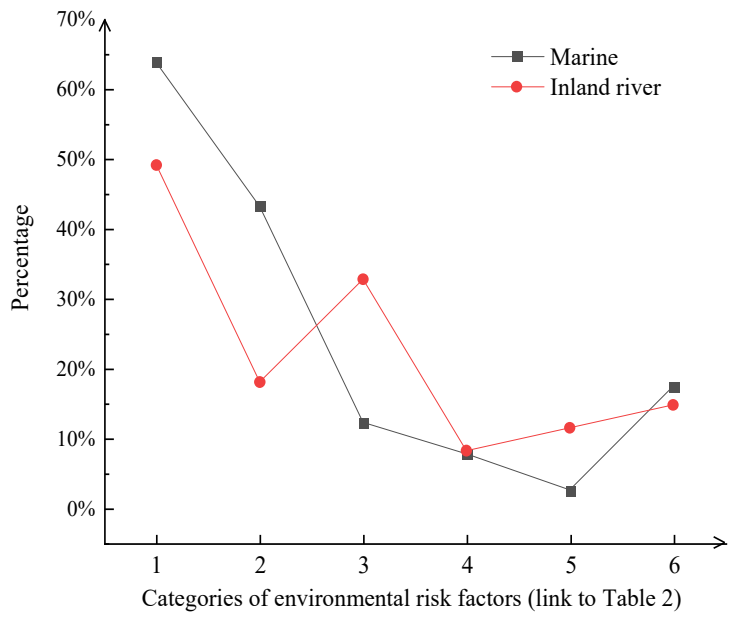

Figure 8. Proportion of Sub-Factors of Marine and Inland River Environmental Factors. 


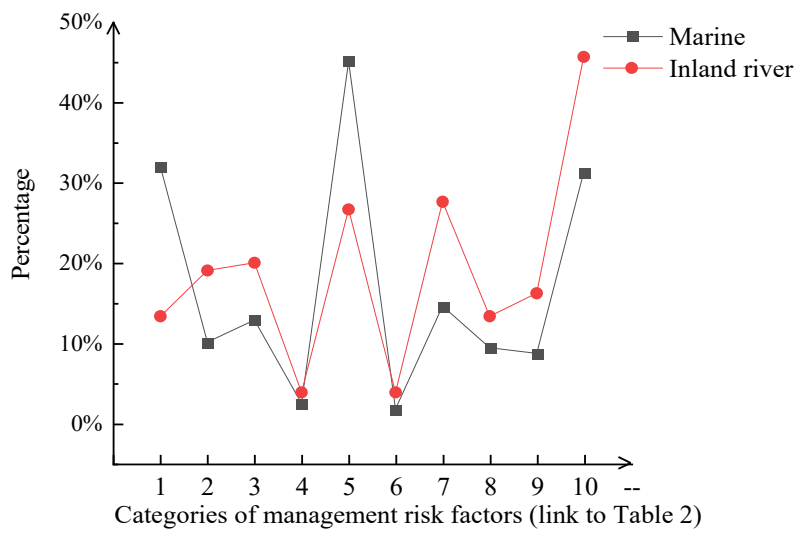

Figure 9. Proportion of Sub-Factors of Marine and Inland River Management Factors.

As shown in Figure 6, the overall trend of the activity of human sub-factors in the cause of marine and inland river accidents is relatively consistent. Among sub-factors, the negligence factor is the most prevalent, reaching about $40 \%$. In maritime accidents, negligence, failure to take early action, and inexperience accounted for a large proportion. In inland rivers, negligence, lack of safety awareness, and failure to take early action accounted for a large proportion. The problem of poor safety awareness is more prominent among inland river accidents, where it takes second place, but poor safety awareness only takes the ninth place in maritime accidents. The sub-factor of improper manipulation is also more prevalent in inland rivers than in the ocean, ranking fourth in inland rivers, and only 9 th in the ocean. A low level of crew education in inland river accidents and complicated conditions of inland waterways exert a greater impact on inland river accidents.

The prevalence of ship sub-factors among the causes of maritime and inland river accidents is basically identical except for uninspected ships, ship overloading, and navigation in high-traffic areas. Equipment failure sub-factors account for the highest proportion, accounting for more than $25 \%$ of the total. Among maritime accidents, equipment failure, navigation in super-navigation areas, and missing equipment account for a larger proportion. In inland rivers, equipment failure, missing equipment, and ship overload account for a large proportion. The factor of overrun area is more prominent in maritime accidents, but rarely present in inland rivers. The problems of equipment failure and lack of equipment are more prominent in marine and inland river accidents. Ship overloading and missed inspection are more prevalent in inland rivers than at sea, ranking 4th and 3rd in inland rivers, but only 6th and 8th at sea, respectively. Uneven ship conditions in inland rivers exert a stronger impact on inland river accidents. Violations of maritime navigation by inland vessels lead to a larger proportion of prevalence of over-traffic areas in maritime accidents.

As shown in Figure 8, the environmental sub-factors basically follow the same trend of activity for both the causes of marine and inland river accidents except for the flow factor. Among them, the wind factor accounts for the largest proportion, with a combined proportion of about $55 \%$. In maritime accidents, environmental factors such as wind and waves account for a larger proportion, while in inland rivers, wind and flow factors account for a larger proportion. The flow factor is more prominent in inland river accidents (i.e., second place), but less prominent (i.e., fourth place) in maritime accidents. The influence of the rain factor on the inland river accidents is also slightly higher than that out at sea. The complex flow patterns in inland rivers, which are prone to bends and bridge areas, exert a stronger impact on inland river accidents. Open sea areas are prone to strong winds and large waves that exert a greater impact on maritime accidents.

As shown in Figure 9, the overall trends of the degrees of activity of the sub-factors of management factors in the causes of maritime and inland river accidents are basically identical. Among them, lack of management and crew discomfort account for more 
than $35 \%$ of the total. In maritime accidents, factors such as unsuitable crew, insufficient manning, and lack of management account for a higher proportion. In inland rivers, factors such as lack of management, lack of training, and unsuitable crew account for a larger proportion. The problem of lack of training is more prominent in inland rivers (i.e., second place), but less prominent (i.e., fourth place) in maritime accidents. The problem of insufficient manning is more prominent among accidents at sea (i.e., second place), but less prominent (i.e., seventh place) in inland rivers. It can be seen that in inland rivers, the failure of shipping companies, ship owners, and ship operators to implement the safety responsibilities of production entities greatly impacts inland river accidents. The problem of manning ships exerts a greater impact on marine accidents.

\section{Methods}

The maritime safety system is complex. The system has self-regulation and self-repair abilities. The self-regulation and self-repair of the system mean that when a risk occurs, it is discovered in time, and measures are taken to solve it to avoid accidents. For example, when the ship is unevenly unloaded and tilted, it is self-regulation within the system to prevent the ship from overturning through timely adjustment of ballast and other measures. Various subsystems influence and interact with each other within the maritime safety system. In general, it is difficult for all risk factors that affect the safety of maritime to overcome the integrated defense system at the same time. Then, the coupling exceeds the maximum threshold the safety system can withstand. This is because specific risk factors gradually reach the global maximum coupling value in the process of coupling after breaking through the local defense system. Therefore, when these specific risk factors reach a local coupling point, they will engage in coupling activities based on this model. The local coupling of risk factors is gradually identified in the process of risk transmission. A risk that cannot be coupled again with the local coupling risk will tend to disappear. Only the risk of coupling with the local coupling risk can continuously lead to a further expansion of the coupling risk. This has led to a specialization of maritime safety risk coupling. The $\mathrm{N}-\mathrm{K}$ model is a general model for studying complex problems. It was initially proposed by Kauffman [19] in 1993 for studying the evolution of biological gene combinations. The $\mathrm{N}-\mathrm{K}$ model can assess the cooperative effect of different components and the complexity status of the system by assessing fitness; therefore, it provides a general analysis tool for the study of complex systems.

The N-K model offers versatility for the analysis of the causes of accidents and is widely used in various fields. Huang et al. [20] used the N-K model to study and analyze the formation mechanism of the coupling risk of the railway transportation system for dangerous goods, and quantitatively described the coupling relationship within this system. Qiao et al. [21] analyzed the coupling relationship between coal mine gas risks from the perspective of single, double, and multiple factors, for which, the N-K model was applied. $\mathrm{Hu}$ et al. [22] used the N-K model and the improved coupling degree model to establish a road traffic risk coupling model under the geological and meteorological environment of the plateau area, and quantified the risk levels of various couplings. Ali and Alireza [23] used the N-K model to study the implementation of the safety constrained unit commitment problem of power system heating units. Ahumada-Paras et al. [24] applied the N-K model to the natural gas pipeline network and proposed a novel cutting plane method to reduce natural gas transportation. In the present paper, the N-K model is applied to the coupling study of maritime accidents.

By applying the trigger principle, the evolution process of maritime accidents is shown in Figure 10. In the process of the transmission of risk factors within the system, after breaking through the sub-defense system, new pulses will be generated after application of the coupling filter. These new pulses will undergo coupling oscillations to increase the risk flow. (Coupling oscillation refers to the interaction of different risk factors within the system.) When the risk breaks through the integrated defense system, maritime accidents 
will occur; alternatively, their risk of occurrence will increase or new risks may be generated, which will then lead to the occurrence of maritime accidents.

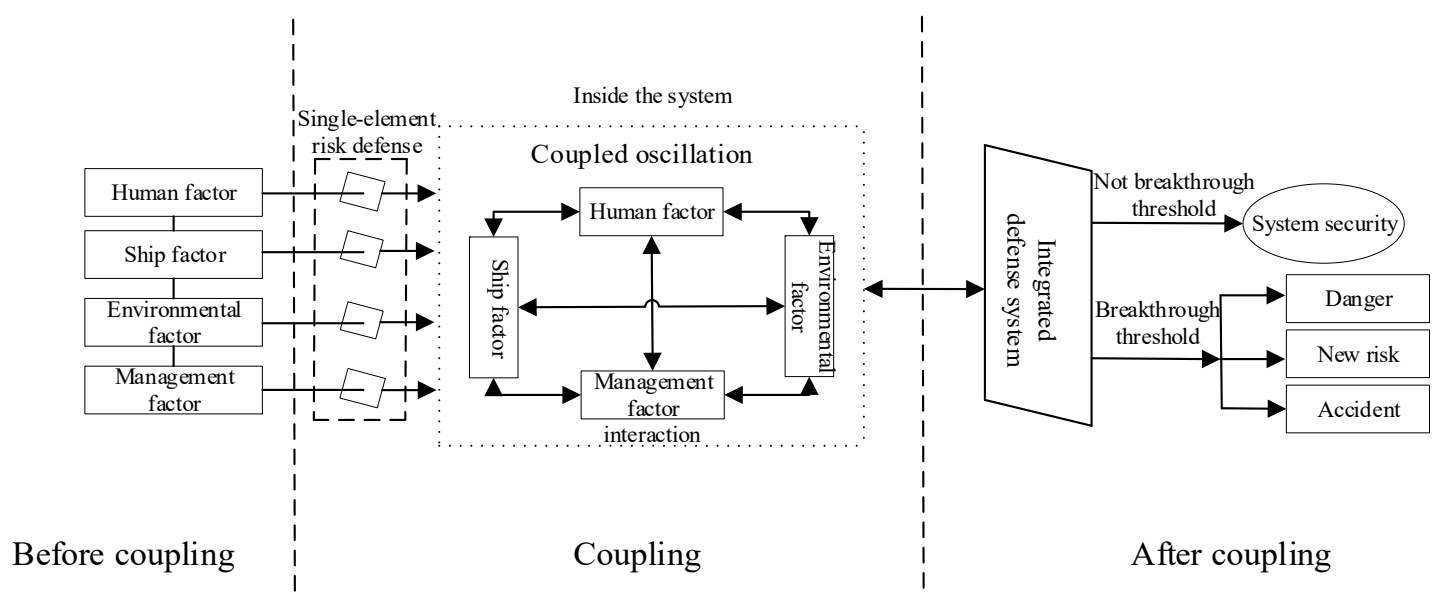

Figure 10. Coupling triggering process of the risk factors of maritime accidents.

The N-K model mainly contains two important parameters: $\mathrm{N}$ and $\mathrm{K}$. When applied to a maritime safety system, $\mathrm{N}$ represents the number of subfactors, and $\mathrm{K}$ represents the number of interactions and mutual couplings among the various subfactors in the maritime traffic safety system. There are $\mathrm{n}$ kinds of mutual combinations among the components of different subfactors, i.e., there are $\mathrm{n}^{\mathrm{K}}$ combinations in total. The value range of $\mathrm{K}$ is $[0, \mathrm{~N}-1]$, and different components can be combined in a certain way to form a network.

According to the number of risk factors involved in the coupling, the risk coupling of maritime accidents can be allocated to the following four categories:

1. Single risk factor coupling refers to the interaction of a certain type of safety sub-factor in the maritime safety system, including the four types of human-human, ship-ship, environmental-environmental, and management-management interactions. The risk coupling values are $T_{11}(\mathrm{a}), T_{12}(\mathrm{~b}), T_{13}(\mathrm{c})$, and $T_{14}(\mathrm{~d})$, respectively.

2. Coupling of two risk factors refers to the interaction of two specific types of factors that affect the maritime safety system. These include the six categories of human-ship, human-environmental, human-management, ship-environmental, ship-management, and environmental-management interactions. The resulting risk coupling values are $T_{21}(a, b), T_{22}(a, c), T_{23}(a, d), T_{24}(b, c), T_{25}(b, d)$, and $T_{26}(c, d)$, respectively. The calculation formula for the coupling of dual risk factors is as follows, where $P$ represents the risk probability.

$$
\begin{aligned}
& T_{21}(a, b)=\sum_{h=1}^{H} \sum_{i=1}^{I} P_{h, i} \cdot \log _{2}\left[P_{h, i} /\left(P_{h} P_{i}\right)\right] \\
& T_{22}(a, c)=\sum_{h=1}^{H} \sum_{j=1}^{J} P_{h, j} \cdot \log _{2}\left[P_{h, j} /\left(P_{h} P_{j}\right)\right] \\
& T_{23}(a, d)=\sum_{h=1}^{H} \sum_{k=1}^{K} P_{h, k} \cdot \log _{2}\left[P_{h, k} /\left(P_{h} P_{k}\right)\right] \\
& T_{24}(b, c)=\sum_{i=1}^{I} \sum_{j=1}^{J} P_{i, j} \cdot \log _{2}\left[P_{i, j} /\left(P_{i} P_{j}\right)\right] \\
& T_{25}(b, d)=\sum_{i=1}^{I} \sum_{k=1}^{K} P_{i, k} \cdot \log _{2}\left[P_{i, k} /\left(P_{i} P_{k}\right)\right]
\end{aligned}
$$




$$
T_{26}(c, d)=\sum_{j=1}^{J} \sum_{k=1}^{K} P_{j, k} \cdot \log _{2}\left[P_{j, k} /\left(P_{j} P_{k}\right)\right]
$$

3. Coupling of three risk factors refers to the interaction between three specific types of factors that affect the maritime safety system; the resulting coupling value is represented by $T_{3}$. This includes the following four types of interactions: human-shipenvironmental, human-ship-management, human-environmental-management, and ship-environmental-management. The risk coupling values are $T_{31}(a, b, c), T_{31}(a, b, d)$, $T_{33}(\mathrm{a}, \mathrm{c}, \mathrm{d})$, and $T_{34}(\mathrm{~b}, \mathrm{c}, \mathrm{d})$, respectively. The calculation formulae for the three-factor risk coupling are:

$$
\begin{aligned}
& T_{31}(a, b, c)=\sum_{h=1}^{H} \sum_{i=1}^{I} \sum_{j=1}^{J} P_{h, i, j} \cdot \log _{2}\left[P_{h, i, j} /\left(P_{h} P_{i} P_{j}\right)\right] \\
& T_{32}(a, b, d)=\sum_{h=1}^{H} \sum_{i=1}^{I} \sum_{k=1}^{K} P_{h, i, k} \cdot \log _{2}\left[P_{h, i, k} /\left(P_{h} P_{i} P_{k}\right)\right] \\
& T_{33}(a, c, d)=\sum_{h=1}^{H} \sum_{j=1}^{J} \sum_{k=1}^{K} P_{h, j, k} \cdot \log _{2}\left[P_{h, j, k} /\left(P_{h} P_{j} P_{k}\right)\right] \\
& T_{34}(b, c, d)=\sum_{i=1}^{I} \sum_{j=1}^{J} \sum_{k=1}^{K} P_{i, j, k} \cdot \log _{2}\left[P_{i, j, k} /\left(P_{i} P_{j} P_{k}\right)\right]
\end{aligned}
$$

4. Coupling of four risk factors refers to the interaction between the four types of factors that affect the maritime traffic safety system, namely, the risk coupling of human-shipenvironmental-management. The generated coupling value is represented by T4, and the calculation formula for the coupling of the four risk factors is presented in the following:

$$
T_{4}(a, b, c, d)=\sum_{h=1}^{H} \sum_{i=1}^{I} \sum_{j=1}^{J} \sum_{k=1}^{K} P_{h, i, j, k} \cdot \log _{2}\left[P_{h, i, j, k} /\left(P_{h} P_{i} P_{j} P_{k}\right)\right]
$$

\section{Results and Discussion}

This section is divided by subheadings. It should provide a concise and precise description of the experimental results, their interpretation, as well as the experimental conclusions that can be drawn.

\subsection{Coupling Calculation of Risk if Marine and Inland River Accidents}

\subsubsection{Risk Coupling Frequency Analysis of Maritime Accidents}

The report data of 922 maritime accidents in Chinese waters was analyzed. The two major categories of marine accidents and inland river accidents were separately calculated by the N-K model, to analyze the coupling characteristics of inland rivers and oceans and different accident types. The details are shown in Tables 3 and 4. 
Table 3. Number and frequency of risk coupling of marine accidents.

\begin{tabular}{|c|c|c|c|c|c|c|c|}
\hline \multirow{2}{*}{$\begin{array}{l}\text { Single Risk Factor } \\
\text { Coupling }\end{array}$} & Number & $n_{0000}=0$ & $n_{1000}=161$ & $n_{0100}=19$ & $n_{0010}=5$ & $n_{0001}=4$ & $\longrightarrow$ \\
\hline & Frequency & $\begin{array}{c}p_{0000}= \\
0.0000\end{array}$ & $\begin{array}{c}p_{1000}= \\
0.2597\end{array}$ & $\begin{array}{c}p_{0100}= \\
0.0306\end{array}$ & $\begin{array}{c}p_{0010}= \\
0.0081\end{array}$ & $\begin{array}{c}p_{0001}= \\
0.0065\end{array}$ & 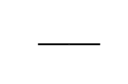 \\
\hline \multirow{2}{*}{$\begin{array}{l}\text { Coupling of two risk } \\
\text { factors }\end{array}$} & Number & $n_{1100}=75$ & $n_{1010}=44$ & $n_{1001}=80$ & $n_{0110}=12$ & $n_{0101}=13$ & $n_{0011}=3$ \\
\hline & Frequency & $\begin{array}{c}p_{1100}= \\
0.1210\end{array}$ & $\begin{array}{c}p_{1010}= \\
0.0710\end{array}$ & $\begin{array}{c}p_{1001}= \\
0.1290\end{array}$ & $\begin{array}{c}p_{0110}= \\
0.0194\end{array}$ & $\begin{array}{c}p_{0101}= \\
0.0210\end{array}$ & $\begin{array}{c}p_{0011}= \\
0.0048\end{array}$ \\
\hline \multirow{2}{*}{$\begin{array}{c}\text { Coupling of three risk } \\
\text { factors }\end{array}$} & Number & $n_{1110}=16$ & $n_{1101}=111$ & $n_{1011}=28$ & $n_{0111}=15$ & - & - \\
\hline & Frequency & $\begin{array}{c}p_{1110}= \\
0.0258\end{array}$ & $\begin{array}{c}p_{1101}= \\
0.1790\end{array}$ & $\begin{array}{c}p_{1011}= \\
0.0452\end{array}$ & $\begin{array}{c}p_{0111}= \\
0.0242\end{array}$ & 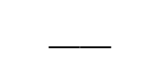 & - \\
\hline \multirow{2}{*}{$\begin{array}{l}\text { Coupling of four risk } \\
\text { factors }\end{array}$} & Number & $n_{1111}=34$ & - & - & - & 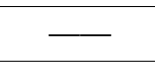 & 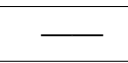 \\
\hline & Frequency & $\begin{array}{c}p_{1111}= \\
0.0548\end{array}$ & 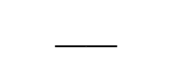 & - & 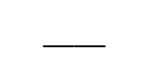 & - & - \\
\hline
\end{tabular}

Table 4. Number and frequency of risk coupling of inland river accidents.

\begin{tabular}{|c|c|c|c|c|c|c|c|}
\hline \multirow{2}{*}{$\begin{array}{l}\text { Single Risk Factor } \\
\text { Coupling }\end{array}$} & Number & $n_{0000}=0$ & $n_{1000}=110$ & $n_{0100}=8$ & $n_{0010}=1$ & $n_{0001}=2$ & $\longrightarrow$ \\
\hline & Frequency & $\begin{array}{c}p_{0000}= \\
0.0000\end{array}$ & $\begin{array}{l}p_{1000}= \\
0.3642\end{array}$ & $\begin{array}{l}p_{0100}= \\
0.0265\end{array}$ & $\begin{array}{l}p_{0010}= \\
0.0033\end{array}$ & $\begin{array}{c}p_{0001}= \\
0.0066\end{array}$ & 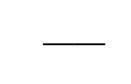 \\
\hline \multirow{2}{*}{$\begin{array}{l}\text { Coupling of two risk } \\
\text { factors }\end{array}$} & Number & $n_{1100}=45$ & $n_{1010}=20$ & $n_{1001}=37$ & $n_{0110}=1$ & $n_{0101}=6$ & $n_{0011}=1$ \\
\hline & Frequency & $\begin{array}{c}p_{1100}= \\
0.1490\end{array}$ & $\begin{array}{l}p_{1010}= \\
0.0662\end{array}$ & $\begin{array}{c}p_{1001}= \\
0.125\end{array}$ & $\begin{array}{c}p_{0110}= \\
0.0033\end{array}$ & $\begin{array}{c}p_{0101}= \\
0.0199\end{array}$ & $\begin{array}{c}p_{0011}= \\
0.0033\end{array}$ \\
\hline \multirow{2}{*}{$\begin{array}{l}\text { Coupling of three risk } \\
\text { factors }\end{array}$} & Number & $n_{1110}=12$ & $n_{1101}=33$ & $n_{1011}=15$ & $n_{0111}=1$ & $\longrightarrow$ & $\longrightarrow$ \\
\hline & Frequency & $\begin{array}{c}p_{1110}= \\
0.0397\end{array}$ & $\begin{array}{l}p_{1101}= \\
0.1093\end{array}$ & $\begin{array}{l}p_{1011}= \\
0.0497\end{array}$ & $\begin{array}{c}p_{0111}= \\
0.0033\end{array}$ & 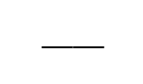 & \\
\hline \multirow{2}{*}{$\begin{array}{l}\text { Coupling of four risk } \\
\text { factors }\end{array}$} & Number & $n_{1111}=10$ & - & - & - & - & - \\
\hline & Frequency & $\begin{array}{c}p_{1111}= \\
0.0331\end{array}$ & 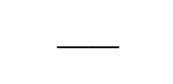 & - & - & - & 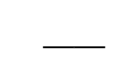 \\
\hline
\end{tabular}

\subsubsection{Calculation of the Coupling Values of the Maritime Accident Risk}

According to the results presented in Section 4.1, the N-K model is used to calculate the probability change of single risk factor, double risk factors, and multiple risk factors.

1 means that such risks are involved, and 0 means that such risks are not involved. Calculation of single risk factor change probability: Taking the single factor change probability of human factors as example, including situations involving ship/environmental/management factors and situations not involving ship/environmental/management factors, the probability of maritime accidents when all human factors are involved in their coupling can be calculated according to Equation (12), Among them, "** means this factor can be "1" or " 0 ".

$$
\mathrm{P}_{1^{* * *}}=\mathrm{P}_{1000}+\mathrm{P}_{1100}+\mathrm{P}_{1010}+\mathrm{P}_{1001}+\mathrm{P}_{1110}+\mathrm{P}_{1101}+\mathrm{P}_{1011}+\mathrm{P}_{1111}=0.8858
$$

The change probability of other single risk factors can be obtained in the same way. The specific calculation results are shown in Table 5.

Table 5. Single-factor change probability of marine accidents.

\begin{tabular}{cccccccc}
\hline $\boldsymbol{p}_{\mathbf{0}^{* * *}}$ & $\boldsymbol{p}_{\mathbf{1}^{* * *}}$ & $\boldsymbol{p}_{* \mathbf{0}^{* *}}$ & $\boldsymbol{p}_{*^{*} \mathbf{1}^{* *}}$ & $\boldsymbol{p}_{* * \mathbf{0}^{*}}$ & $\boldsymbol{p}_{* * \boldsymbol{1}}$ & $\boldsymbol{p}_{* * *}$ & $\boldsymbol{p}_{* * *}$ \\
\hline 0.1145 & 0.8855 & 0.5242 & 0.4758 & 0.7469 & 0.2532 & 0.5355 & 0.4645 \\
\hline
\end{tabular}


Calculation of the probability of double risk factors: If all human factors and ship factors contribute to the coupling at the same time, the probability of the occurrence of a maritime accident can be calculated according to Equation (13):

$$
\mathrm{P}_{11^{* *}}=\mathrm{P}_{1100}+\mathrm{P}_{1110}+\mathrm{P}_{1101}+\mathrm{P}_{1111}=0.3806
$$

The change probability of other double risk factors can be obtained in the same way. The specific calculation results are shown in Table 6.

Table 6. Two-factor change probability of marine accidents.

\begin{tabular}{|c|c|c|c|c|c|c|c|}
\hline$p_{00^{* *}}$ & $p_{01^{* *}}$ & $p_{10^{* *}}$ & $p_{11^{* *}}$ & $p_{0^{*} 0^{*}}$ & $p_{1^{*} 0^{*}}$ & $p_{0^{*} 1^{*}}$ & $p_{1^{*} 1^{*}}$ \\
\hline 0.0194 & 0.0952 & 0.5048 & 0.3806 & 0.0581 & 0.6887 & 0.0565 & 0.1968 \\
\hline$p_{0^{* *} 0}$ & $p_{1^{* *} 0}$ & $p_{1^{* * 1}}$ & $p_{*}^{*} 00^{*}$ & $p^{* 10^{*}}$ & $p_{* 01}^{*}$ & $p_{* 11^{*}}$ & $p_{0^{* *} 1}$ \\
\hline 0.0581 & 0.4774 & 0.4081 & 0.3852 & 0.3516 & 0.1290 & 0.1242 & 0.0565 \\
\hline$p_{*} 0^{*} 0$ & $p^{*} 1^{*} 0$ & $p^{*{ }^{*} 1}$ & $p^{* 1^{*} 1}$ & $p_{* * 00}$ & $p^{* * 10}$ & $p^{* *} 01$ & $p^{* * 11}$ \\
\hline 0.3387 & 0.1968 & 0.1855 & 0.2790 & 0.4113 & 0.1242 & 0.3355 & 0.1290 \\
\hline
\end{tabular}

Multi-factor changes probability calculation: If all human factors, ship factors, and environmental factors are involved in the coupling, the probability of a marine accident can be calculated according to Equation (14):

$$
\mathrm{P}_{111^{*}}=\mathrm{P}_{1110}+\mathrm{P}_{1111}=0.0806
$$

The change probability of other multi-risk factors can be obtained in the same way. The specific calculation results are shown in Table 7.

\begin{tabular}{|c|c|c|c|c|c|c|c|}
\hline$p_{000^{*}}$ & $p_{100^{*}}$ & $p_{010^{*}}$ & $p_{001^{*}}$ & $p_{110^{*}}$ & $p_{101^{*}}$ & $p_{011^{*}}$ & $p_{111^{*}}$ \\
\hline 0.0065 & 0.3887 & 0.0516 & 0.0129 & 0.3000 & 0.1161 & 0.0435 & 0.0806 \\
\hline$p_{* 000}$ & $p_{* 100}$ & $p_{* 010}$ & $p_{* 001}$ & $p_{* 110}$ & $p * 101$ & $p_{* 011}$ & $p * 111$ \\
\hline 0.2597 & 0.1516 & 0.0790 & 0.1355 & 0.0452 & 0.2000 & 0.0500 & 0.0790 \\
\hline$p_{0^{*} 00}$ & $p_{1 * 00}$ & $p_{0 * 10}$ & $p_{0 * 01}$ & $p_{1 * 10}$ & $p_{1 * 01}$ & $p_{0^{*} 11}$ & $p_{1^{*} 11}$ \\
\hline 0.0306 & 0.3806 & 0.0274 & 0.0274 & 0.0968 & 0.3081 & 0.0290 & 0.1000 \\
\hline$p_{00^{*} 0}$ & $p_{10^{*} 0}$ & $p_{01^{*} 0}$ & $p_{00^{*} 1}$ & $p_{11^{*} 0}$ & $p_{10 * 1}$ & $p_{01^{*} 1}$ & $p_{11^{* 1}}$ \\
\hline 0.0081 & 0.3306 & 0.0500 & 0.0113 & 0.1468 & 0.1742 & 0.0452 & 0.2339 \\
\hline
\end{tabular}

Table 7. Multi-factor changes probability of marine accidents.

According to the calculation formula of the N-K model, as constructed in Section 3:

$$
\begin{aligned}
T_{21}(a, b) & =\sum_{h=1}^{H} \sum_{i=1}^{I} P_{h, i} \cdot \log _{2}\left[\frac{P_{h, i}}{\left(P_{h} P_{i}\right)}\right] \\
& =\left(p_{00 * *} \times \log _{2}\left(\frac{p_{00 * *}}{p_{0 * * *} x_{* 0 * *}}\right)\right) \\
& +\left(p_{01 * *} \times \log _{2}\left(\frac{p_{01 * *}}{p_{0 * * *} \times p_{* 1 * *}}\right)\right)\left(p_{10 * *} \times \log _{2}\left(\frac{p_{10 * *}}{p_{1 * * *} \times p_{* 0 * *}}\right)\right)\left(p_{11 * *} \times \log _{2}\left(\frac{p_{11 * *}}{p_{1 * * *} \times p_{* 1 * *}}\right)\right)=0.0504
\end{aligned}
$$

The results of each risk coupling value $\mathrm{T}$ can also be obtained as shown in Table 8 . 
Table 8. Risk Coupling Values of Marine Accidents.

\begin{tabular}{|c|c|c|c|c|c|}
\hline Coupling Value & Sort & Coupling Value & Sort & Coupling Value & Sort \\
\hline$T_{21}=0.0504$ & 4 & $T_{25}=0.0395$ & 6 & $T_{33}=0.0273$ & 7 \\
\hline$T_{22}=0.0252$ & 8 & $T_{26}=0.0020$ & 9 & $T_{34}=0.0974$ & 2 \\
\hline$T_{23}=0.0003$ & 10 & $T_{31}=0.0779$ & 3 & $T_{4}=0.1353$ & 1 \\
\hline$T_{24}=0.0002$ & 11 & $T_{32}=0.0415$ & 5 & & 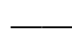 \\
\hline
\end{tabular}

Following the same steps, the risk coupling value of inland river accidents can be obtained as shown in Table 9.

Table 9. Risk Coupling Values of Inland River Accidents.

\begin{tabular}{cccccc}
\hline Coupling Value & Sort & Coupling Value & Sort & Coupling Value & Sort \\
\hline$T_{21}=0.0371$ & 4 & $T_{25}=0.0137$ & 6 & $T_{33}=0.0127$ & 7 \\
$T_{22}=0.000001$ & 11 & $T_{26}=0.0071$ & 8 & $T_{34}=0.0594$ & 2 \\
$T_{23}=0.0050$ & 9 & $T_{31}=0.0436$ & 3 & $T_{4}=0.0800$ & 1 \\
$T_{24}=0.00007$ & 10 & $T_{32}=0.0234$ & 5 & & - \\
\hline
\end{tabular}

4.1.3. Analysis of Risk Coupling Characteristics of Maritime and Inland River Accidents

The calculated risk coupling value of marine and inland river accidents is shown in Figure 11.

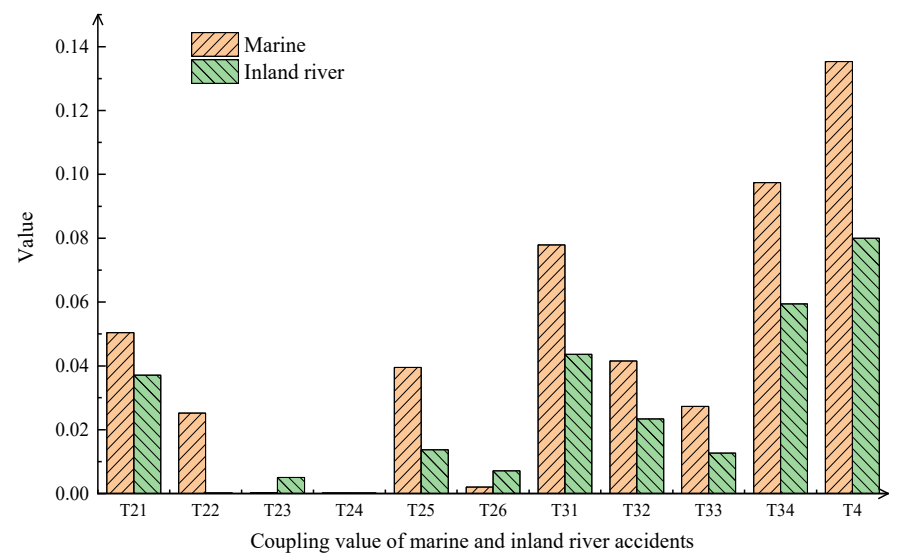

Figure 11. Coupling value of risk factors of marine and inland river accidents.

Among the risk coupling values of marine accidents, the coupling value $T_{4}$ of the four-factor coupling of human-ship-environmental-management is highest, and the probability that this causes marine accidents is also highest. In the three-factor coupling, $T_{34}$ $>T_{31}>T_{32}>T_{33}$, and the coupling values of the two coupling modes of human-shipenvironmental and ship-environmental-management are relatively large. The value of the coupling of human-ship-managemental and human-environmental-management is relatively small. When ship factors and environmental factors participate simultaneously, traffic accidents are more likely caused when subjective factors (i.e., human factors or management factors) are coupled. In two-factor coupling, $T_{21}>T_{25}>T_{22}>T_{26}>T_{23}>T_{24}$, and the coupling values of the three coupling modes of human-ship, human-environmental, and ship-management are much higher than those of the three coupling modes of humanmanagement, ship-environmental, and environmental-management. When human factors and objective factors are coupled, ship factors and subjective factors are more likely to be coupled when causing accidents.

Among the risk coupling values of inland river accidents, the coupling value $T_{4}$ of the four-factor coupling of human-ship-environmental-management is highest, and the 
probability that all four factors simultaneously participate in the coupling is also highest. In the three-factor coupling, $T_{34}>T_{31}>T_{32}>T_{33}$, the probability that objective factors such as ship factors and environmental factors simultaneously participate in coupling accidents is higher than the probability that subjective factors (i.e., human factors and management factors) simultaneously participate in coupling accidents. In the two-factor coupling, $T_{21}$ $>T_{25}>T_{26}>T_{23}>T_{24}>T_{22}$, the coupling value of the two coupling modes of man-ship and ship-management is much higher than the values of other coupling modes. Therefore, accidents are more likely caused when ship factors and subjective factors (i.e., human factors or management factors) are coupled.

In general, with the increase of a number of coupling factors, the coupling value increases, and the probability of maritime accidents increases. Marine and inland river accidents have the highest risk value when four factors are coupled, and in this case, the probability of maritime accidents is highest. In three-factor coupling, the trend of coupling values between inland rivers and oceans is more consistent. Although the risk value of specific two-factor coupling exceeds that of three-factor coupling, the risk value of threefactor coupling is higher than that of two-factor coupling as a whole. When objective factors such as ship factors and environmental factors simultaneously participate in the coupling, the risk is higher than when subjective factors simultaneously participate in the coupling. Combined with the two-factor coupling value, the coupling value of the ship-loop coupling method is lower. Therefore, when objective factors simultaneously participate in the coupling, the system is more prone to safety accidents under the guidance of subjective factors. The connection between different factors can be severed by controlling subjective factors with the goal to prevent multi-factor coupling. In the two-factor coupling, the risk values of the two coupling modes of human-ship and ship-management in both inland rivers and the ocean take first and second places, respectively. However, in the coupling of marine accidents, the coupling value of the human-environmental coupling method far exceeds that of the inland river, ranking third, while inland river two-factor coupling is last. Relative to inland river accidents, environmental factors exert an increased influence on marine accidents. In addition, the risk value of the two coupling modes of human-management and environmental-management is higher in inland rivers than in the marine environment. Management factors exert a stronger impact on inland river marine accidents.

\subsection{Analysis of Risk Coupling Characteristics of Different Types of Maritime Accidents}

Different types of maritime accidents have different risk causes, and their risk coupling characteristics are also different. To analyze the risk coupling characteristics of different types of maritime accidents, 922 maritime accidents were collected and classified according to the following six types of maritime accidents: collision, contact, sinking, fire/explosion, stranding, and grounding. Using a similar method to that described in Section 4, the risk coupling values of various types of traffic accidents are calculated, and the results are shown in Figure 12.

Table 10 shows the classifications of the coupling values of different types of accidents, and of the top six risk factor combinations from high to low.

According to the comparative analysis of the coupling results, a slightly different the rankings of the coupling values of different types of accidents risk are slightly different, but the result implies a certain commonality in general. The risk coupling of different types of accidents has different coupling characteristics, and the factors that cause accidents in the coupling are also quite different, as detailed in the following.

In collision accidents, the coupling value of the four risk factors is highest, leading to the highest accident probability. In the three-factor coupling, the coupling values of the three coupling modes of human-ship-environmental, human-ship-management, and shipenvironmental-management are higher, while the coupling value of the coupling mode of human-environmental-management is much lower. When human factors or management factors participate in the coupling, ship factors are more likely to cause collision accidents. 
In the two-factor coupling, the coupling values of the two coupling modes of humanship and ship-management are significantly higher than those of other coupling modes. Similar to the three-factor coupling value, when subjective factors (i.e., human factors and management factors) are coupled with ship factors, collisions are more likely to occur. When ship factors are coupled with other factors, the risk of collision accidents remains high, which is the main accident that needs to be prevented.
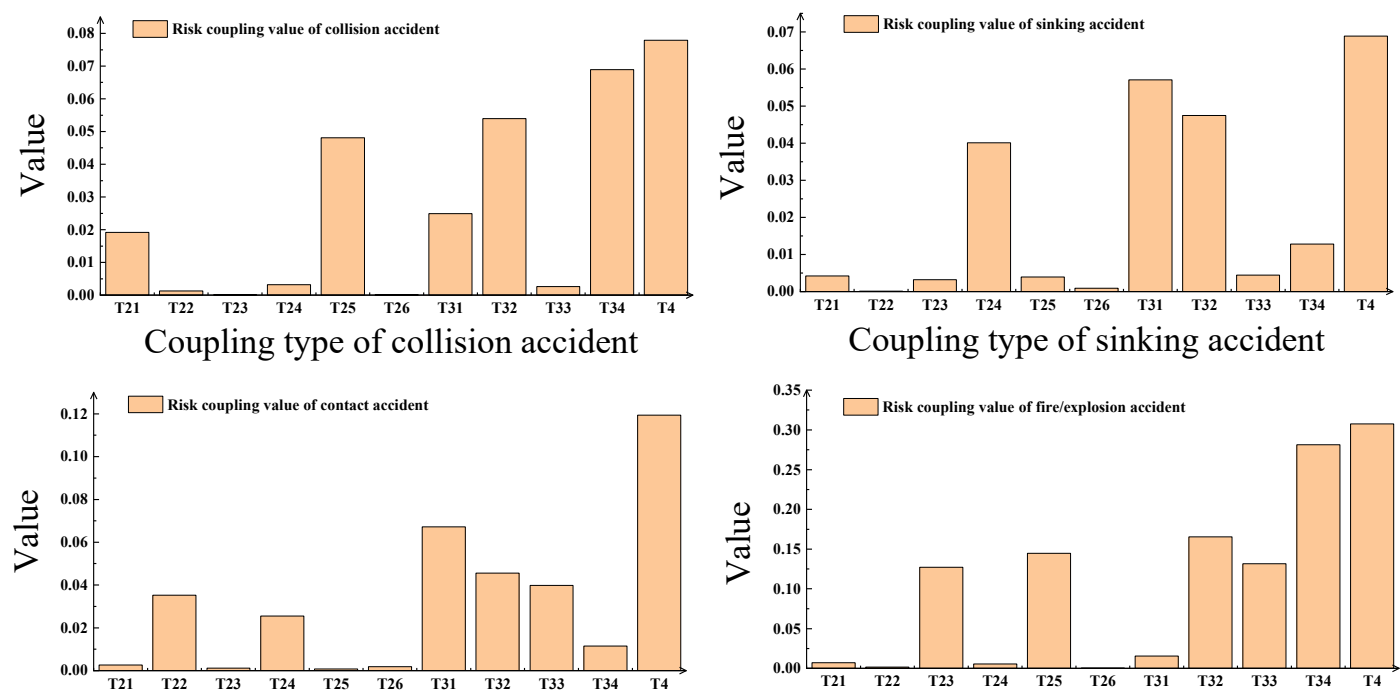

Coupling type of contact accident
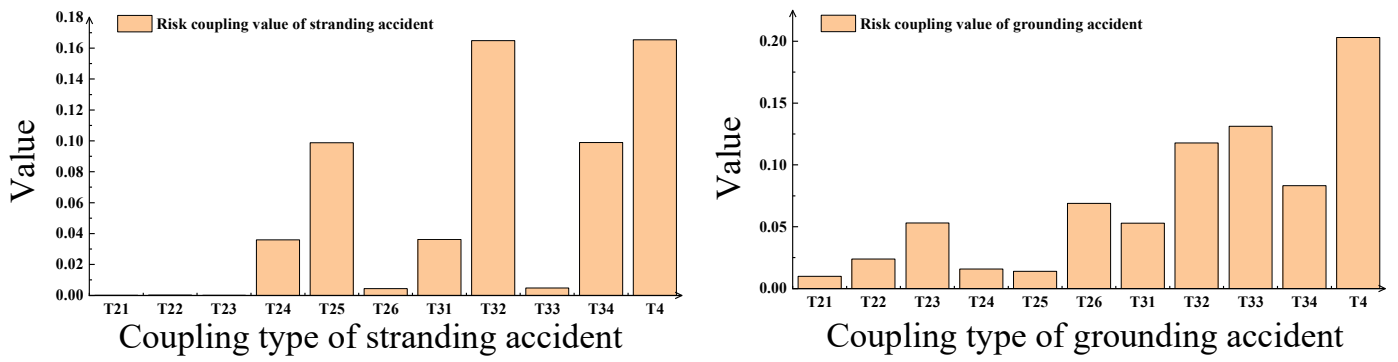

Figure 12. Risk coupling value of different types of accidents.

In sinking accidents, the four risk factors have the highest coupling value, leading to the highest probability that accidents occur. In the three-factor coupling, the coupling values of the two coupling modes of human-ship-environmental and human-ship-management are higher, and the coupling values of the two coupling modes of human-environmentalmanagement and ship-environmental-management are lower. Human factors and ship factors participate in the two coupling modes with higher coupling values among the three factors. Therefore, human factors and ship factors are the two most dangerous factors in sinking accidents. In two-factor coupling, the coupling value of the ship-environmental coupling method is much higher than the other coupling modes. The risk of objective factors in sinking accidents is higher than that of subjective factors. Especially when the two objective factors of ship and environment simultaneously participate in the coupling, the probability that a sinking accident occurs is relatively high.

Among contact accidents, the four risk factors have the highest coupling value, leading to the highest probability of accidents. In the three-factor coupling, the coupling value decreases in the order of human-ship-environmental, human-ship-management, human-environmental-management, and ship-environmental-management. Human factors are more dangerous in contact accidents, and contact accidents are more likely to occur when human factors are coupled with the two objective factors of ship and environment. In the two-factor coupling, the coupling values of the two coupling modes of 
human-environmental and ship-environmental are much higher than those of the other four coupling modes. In both of these coupling modes, environmental factors participate in the coupling. Therefore, environmental factors are also highly dangerous in contact accidents. Especially when environmental factors and human factors simultaneously participate in the coupling, the probability of contact accidents increases.

Table 10. Sorting of coupling values of different types of accidents.

\begin{tabular}{|c|c|c|c|}
\hline \multirow{2}{*}{ Sorting Number } & \multicolumn{3}{|c|}{ Type of Accident } \\
\hline & Collision & Contact & Sinking \\
\hline 1 & Human-ship-environmental-management & Human-ship-environmental-management & Human-ship-environmental-management \\
\hline 2 & Ship-environmental-management & Human-ship-environment & Human-ship-environmental \\
\hline 3 & Human-ship-management & Human-ship-management & Human-ship-management \\
\hline 4 & Ship-management & Ship-management & Human-environmental-management \\
\hline 5 & Human-ship-environmental & Ship-environmental-management & Human-environmental \\
\hline \multirow[t]{2}{*}{6} & Human-ship & Human-environmental-management & Ship-environmental \\
\hline & Fire/explosion & Stranding & Grounding \\
\hline 1 & Human-ship-environmental-management & Human-ship-environmental-management & Human-ship-environmental-management \\
\hline 2 & Ship-environmental-management & Human-ship-management & Human-environmental-management \\
\hline 3 & Human-ship-management & Ship-environmental-management & Human-ship-management \\
\hline 4 & Ship-management & Ship-management & Ship-environmental-management \\
\hline 5 & Human-ship-management & Human-ship-environmental & Environmental-management \\
\hline 6 & Human-management & Ship-environmental & Human-management \\
\hline
\end{tabular}

In fire/explosion accidents, the four risk factors have the highest coupling value, leading to the highest accident probability. In the three-factor coupling, the three coupling modes of ship-environmental-management, human-ship-management, and humanenvironmental-management have higher coupling values, while the coupling value of human-ship-environmental coupling is smaller. In all coupling methods with higher coupling values, management factors are involved in the coupling. Therefore, in fire/explosion accidents, management factors impose a higher risk. The coupling value of the shipenvironmental-management coupling mode is far higher than the two coupling modes of human-ship-management and human-environmental-management. Therefore, when the two objective factors of ship and environment participate in the coupling at the same time and the management factors impose risks, the probability of fire/explosion accidents is greater. In the two-factor coupling, the coupling values of the ship-management and human-management coupling modes are much higher than the four other coupling modes, and in these two coupling modes, management factors are involved in the coupling. Therefore, in fire/explosion accidents, management factors are most dangerous, followed by ship factors, and human factors. In fire/explosion accidents, environmental factors are less dangerous than other risk factors.

In stranding accidents, the four risk factors have the highest coupling value, leading to the highest probability that accidents occur. In the three-factor coupling, the coupling value of the two coupling modes of human-ship-managemental and ship-environmentalmanagement are higher, followed by the human-ship-environmental, and the coupling value of the human-ship-management coupling method. In the coupling mode with higher coupling value, both ship and management are involved in the coupling. In addition, because the coupling value of the human-ship-management coupling method is significantly higher than other coupling values, when both ship and management are involved in the coupling, and when human factors impose risk, the probability that stranding accidents occur will greatly increase. In the two-factor coupling, the coupling values of the shipmanagement and ship-environmental coupling modes are much higher than the other four coupling modes. Therefore, ship factors impose the highest risk on stranding accidents, while environmental factors and management factors are also highly dangerous.

In grounding accidents, the coupling value of the four risk factors is highest, leading to the greatest probability of accidents. In the three-factor coupling, the coupling values of the two coupling modes of human-environmental-management and human-ship-management are higher, followed by the two coupling modes of ship-environmental-management and 
human-ship-environmental. Human and management factors are involved in the coupling of the two higher coupling methods. If the two subjective factors of human and management are completely coupled and objective factors are involved in the coupling, grounding accidents are more likely to occur. In the two-factor coupling, the environmentalmanagement and human-management coupling modes have higher coupling values, followed by the human-environmental and ship-environmental coupling modes, while the coupling values of ship-management and human-ship coupling modes are relatively low. Therefore, in grounding accidents, the two subjective factors of human and management are more dangerous. In addition, the risk of environmental factors is also high, while ship factors impose less influence on the occurrence of grounding accidents.

In general, comparing various types of maritime accidents shows that the characteristics of risk coupling have the following commonalities:

- With increasing risk factors involved in the coupling, the coupling value increases, and the probability of accidents increases.

- The coupling values of the four risk factors of all types of accident risk coupling are highest, and the probability of causing an accident is also highest.

- In the three-factor coupling, although specific two-factor couplings have higher risk values than three-factor couplings, three-factor coupling values generally exceed two-factor coupling values. However, in different types of accidents, the dominant risk factors differ. In the human-ship-environmental coupling, the coupling value of the collision accidents is highest, followed by the coupling value of sinking accidents, and the coupling value of the grounding accidents. In the two coupling modes of human-ship-management and ship-environmental-management, the coupling value of fire/explosion accident is highest, followed by the coupling value of stranding accident, and the coupling value of grounding accident. In the coupling of human-environmental-management, the coupling value of fire/explosion accident still remains highest, followed by the coupling value of grounding accident, and the coupling value of contact accident.

- In the two-factor coupling, in the human-ship coupling, the coupling value of collision accidents is highest, and the coupling values of other types of accidents all remain low and the difference is small. In the human-environmental coupling, the coupling value of contact accidents is highest, followed by grounding accidents, and the coupling values of the other four types of accidents are small. In the human-management coupling, the coupling value of fire/explosion accidents is highest, which is followed by the coupling value of grounding accidents, and the coupling value of other types of accidents is smaller. In the ship-environmental coupling, the coupling value of fire/explosion accidents and collision accidents is relatively low, and the coupling values of other types of accidents are relatively close. They decrease in the order of sinking accidents, stranding accidents, contact accidents, and grounding accidents. In the ship-management coupling, the coupling values of collision accidents, fire/explosion accidents, and stranding accidents far exceed those of other types of accidents. In the environmental-management coupling, only grounding accidents have high coupling values, while other types of accidents have low coupling values.

- In collision and sinking accidents, the two factors of human-ship impose a higher risk. Human factors are more dangerous for contact accidents, followed by shipenvironmental factors. In fire/explosion accidents, ship-management factors are more dangerous, followed by human factors. Ship-management factors are the most dangerous for stranding accidents, followed by environmental factors. In grounding accidents, human-management factors impose higher risk, followed by environmental factors.

- In the coupling of maritime accidents, both human factors and ship factors are key coupling factors. If people and ships are at risk, maritime accidents are more likely to occur. With increasing risk factors increase and more risk factors involved in the coupling, the probability of the occurrence of an accident increases. 


\section{Conclusions}

This paper analyzes 922 maritime accidents in Chines over the past 20 years. The types of accidents, the water area where accident occurred, the number of casualties, the level of accidents, the causes of accidents, and the sub-factors of the accident risk factor are analyzed.

Based on the analysis of the causes of the accident as reported in the accident investigation report, statistical analysis of the cause of the accident is conducted. According to two classification methods of different water areas and different accident types, the N-K model is applied for analysis and calculation. The single-factor change probability, double-factor change probability, multi-factor change probability, and risk coupling value of the accident are calculated, and the calculation results are compared and analyzed.

For marine and inland river accidents, the more risk factors are involved in the coupling, the higher the probability of accidents becomes. According to the calculation results, the four risk factors have the highest coupling value, indicating that the risk is also the highest. Multi-factor coupling should be avoided as much as possible. In inland river and marine accidents, both human factors and ship factors are more dangerous than other factors. The risk of management factors is higher in inland river accidents than at sea. In marine accidents, environmental factors are more dangerous than in inland river accidents.

For different types of accidents: In collision accidents, human factors and ship factors impose a higher risk, followed by management factors. In sinking accidents, human factors and ship factors impose a higher risk, and the overall risk of objective factors is higher than that imposed by subjective factors. When the ship-environmental is simultaneously coupled, the probability of accidents is higher. In contact accidents, human factors impose a higher risk, followed by environmental factors, especially when human factors and environmental factors are coupled with a higher probability of the occurrence of accidents. In fire/explosion accidents, management factors are more dangerous, followed by ship factors and human factors. If management factors are coupled with ship and environmental factors, the probability of accidents is particularly higher. In stranding accidents, ship factors are more dangerous, followed by management factors and environmental factors. In grounding accidents, human factors and management factors are more dangerous, followed by environmental factors, while ship factors are relatively less dangerous.

For the study of accident coupling factors, targeted measures are taken in maritime supervision to avoid the occurrence of multi-factor coupling. For example, strengthening the overhaul and maintenance of ships can prevent ship factors from participating in the coupling; timely reporting of extreme weather enables the crew to take countermeasures in advance and avoid environmental factors from participating in the coupling, which can reduce the occurrence of accidents to a certain extent. In the future, research can be carried out in conjunction with data from other countries' maritime traffic accidents and the success maneuvering data to seek more popular research results. At present, only accidents in China are included, and the application in the waters of other countries needs further research.

Author Contributions: Conceptualization, J.D.; methodology, J.D.; software, S.L.; validation, J.D. and C.X.; formal analysis, C.X.; data curation, C.X.; writing-original draft preparation, S.L. and C.X.; writing-review and editing, J.D. and K.L.; visualization, S.L. and C.X.; supervision, J.D.; project administration, K.L.; funding acquisition, K.L. All authors have read and agreed to the published version of the manuscript.

Funding: This research was funded by The National Natural Science Foundation of China, grant number 52031009.

Conflicts of Interest: The authors declare no conflict of interest. 


\section{References}

1. Ministry of Transport of China. Announcement of the 2020 Transcript of the Transportation Industry. 2021. Available online: https:/ / www.mot.gov.cn/jiaotongyaowen/202105/t20210519_3594381.html (accessed on 20 December 2021).

2. Chen, J.; Di, Z.; Shi JShu, Y.; Wan, Z.; Song, L.; Zhang, W. Marine oil spill pollution causes and governance: A case study of Sanchi tanker collision and explosion. J. Clean. Prod. 2020, 273, 122978. [CrossRef]

3. Mou, J.M.; Tak, C.V.; Ligteringen, H. Study on collision avoidance in busy waterways by using AIS data. Ocean Eng. 2010, 37, 483-490. [CrossRef]

4. Antao, P.; Guedes Soaress, C. Fault-tree models of accident scenarios of RoPax vessels. Int. J. Autom. Comput. 2006, 3, 107-116. [CrossRef]

5. Kim, T.E.; Nazir, S.; Ivar Øvergård, K. A STAMP-based causal analysis of the Korean Sewol ferry accident. Saf. Sci. 2016, 83, 93-101. [CrossRef]

6. Szczepaniak, P.; Jastrzębski, G.; Sibilski, K.; Bartosiewicz, A. The Study of Aircraft Accidents Causes by Computer Simulations. Aerospace 2020, 7, 41. [CrossRef]

7. Zhang, J.W.; Ma, X.X.; Liu, Y.; Qiao, W.L. Cause analysis of ship collision accident based on FRAM-FAHP method. Saf. Environ. Eng. 2021, 28, 29-35.

8. Liu, S.S.; Zheng, Z.Y. Causes of ship collision accident based on Petri nets. J. Dalian Marit. Univ. 2010, 36, 5-7.

9. Liu, Q.; Wang, G.X. Analysis of the coupling mechanism of ship navigation safety risks in complicated waters. J. Wuhan Univ. Technol. Transp. Sci. Eng. 2014, 38, 59-63.

10. Wang, H.X.; Liu, Z.J. Coupling analysis of the risk factors for the maritime transportation safety based on the N-K model. J. Saf. Environ. 2021, 21, 56-61.

11. Luo, F.; Liu, T.Q. Air traffic safety coupling risk analysis based on N-K model. J. Wuhan Univ. Technol. (Inf. Manag. Eng. Ed.) 2011, $33,267-270$

12. Xue, Y.T.; Xiang, P.C.; Jia, F.Y.; Liu, Z.W. Risk Assessment of High-Speed Rail Projects: A Risk Coupling Model Based on System Dynamics. Int. J. Environ. Res. Public Health 2020, 17, 5307. [CrossRef]

13. Jiao, J.; Wei, M.W.; Yuan, Y.; Zhao, T.D. Risk Quantification and Analysis of Coupled Factors Based on the DEMATEL Model and a Bayesian Network. Appl. Sci. 2020, 10, 317. [CrossRef]

14. Liu, K.Z.; Yu, Q.; Yuan, Z.T.; Yang, Z.S.; Shu, Y.Q. A systematic analysis for maritime accidents causation in Chinese coastal waters using machine learning approaches. Ocean Coast. Manag. 2021, 213, 105859. [CrossRef]

15. Yu, Y.; Chen, L.M.; Shu, Y.Q.; Zhu, W.Y. Evaluation model and management strategy for reducing pollution caused by ship collision in coastal waters. Ocean Coast. Manag. 2020, 203, 105446. [CrossRef]

16. Statistical Measures for Maritime Accidents. 2002. Available online: http://www.gov.cn/gongbao/content/2003/content_62152. htm (accessed on 20 December 2021).

17. Chang, Y.H.; Wang, Y.C. Significant human risk factors in aircraft maintenance technicians. Safety Sci. 2010, 48, 54-62. [CrossRef]

18. Pitman, S.J.; Wright, M.; Hocken, R. An analysis of lifejacket wear, environmental factors, and casualty activity on marine accident fatality rates. Saf. Sci. 2019, 111, 234-242. [CrossRef]

19. Kauffman, S.A. The Origins of Order Self-Organization and Selection in Evolution; Oxford University Press: New York, NY, USA, 1993; pp. 40-67.

20. Huang, W.C.; Shuai, B.; Sun, Y. Research on the formation mechanism of coupling risk of railway dangerous goods transportation system based on N-K model. J. China Railw. Soc. 2019, 41, 1-9.

21. Qiao, W.G.; Li, X.C.; Liu, Q.L. Analysis on the Causes of Coal Mine Major Gas Accident Risk Coupling under N-K Model. Sci. Technol. Manag. Res. 2017, 37, 196-200.

22. Hu, L.W.; Xue, G.; Li, L.Y.; Wang, M.; She, T.Y. Analysis of Coupling of Highway Traffic Risks in Geological and Meteorological Environment of Plateau Regions. China J. Highw. Transp. 2018, 31, 110-119.

23. Ali, A.S.; Alireza, S. Proposing a New Model for Security Constraint Unit Commitment Problem, Considering Network. Indian J. Eng. 2015, 12, 169-175.

24. Ahumada-Paras, M.; Sundar, K.; Bent, R.; Zlotnik, A. N-k interdiction modeling for natural gas networks. Electr. Power Syst. Res. 2021, 190, 106725. [CrossRef] 